\title{
COMPARANDO LOS MODELOS UNIVERSITARIOS BRITÁNICO Y ESPAÑOL
}

\section{COMPARING THE BRITISH AND SPANISH UNIVERSITY MODELS}

\section{AUTORES}

Leonardo García Sanjuán: Department of Archaeological Sciences. University of Bradford.

Horton Building, Richmond Road. Bradford, BD71DP. United Kingdom.

Tel: +44 (0) 1274-235532, Fax: +44 (0) 1274-235190

L.Garcia@bradford.ac.uk

\section{CURRÍCULUM VITAE}

Doctor en Historia. Profesor Titular. Departamento de Prehistoria y Arqueología. Universidad de Sevilla. Sus principales temas de investigación son la arqueología de la desigualdad social en la Prehistoria Reciente del Sur de la Península Ibérica, las prácticas funerarias y la dimensión espacial, territorial y paisajística del registro arqueológico.

\section{RESUMEN}

El debate propuesto en esta sección de Vivat Academia sobre modelos de carrera universitaria es tanto más interesante y oportuno cuanto que a mi juicio está claro que en el momento actual se está abriendo en nuestro país un periodo de profunda reflexión y autocrítica sobre nuestro actual modelo universitario. Esta reflexión viene marcada sin duda por el bochorno desatado entre muchos académicos españoles por 
el famoso editorial de Nature (Diciembre de 1998) sobre la endogamia académica nacional, pero creo que, como está dejando claro el excelente foro de discusión propuesto por la AACTENOTA1, tiene mucho más alcance, yendo más allá del problema concreto del lamentable derrotero que ha seguido el sistema de contrataciones de investigadores y profesores en buena parte de nuestra universidad, y afectando en general a muchos aspectos del diseño y conceptualización de la institución universitaria.

\title{
PALABRAS CLAVE
}

Modelos - Nature - Universidad

\begin{abstract}
The proposed discussion in this section of Vivat Academia on university models is the more interesting and timely in that in my opinion it is clear that at the moment is making our country a period of deep reflection and self-criticism of our current university model. This reflection is dictated no doubt by the embarrassment of many Spanish academics unleashed by the famous publisher of Nature (December 1998) on national academic inbreeding, but I think that, as is making it clear the excellent forum for discussion proposed by the AACTENOTA1 has more far reaching, going beyond the specific problem of the unfortunate course that has followed the system of recruitment of researchers and teachers in most of our university, and generally affect many aspects of the design and conceptualization of the university.
\end{abstract}

\section{KEY WORDS}

Models - Nature - University 


\section{ÍNDICE}

1. Introducción

2. Descripción del Modelo Británico

1.1. Un Modelo Altamente Competitivo

1.2. Sistema Docente

3. ¿Flexibilidad vs. Rigidez? Discusión Comparativa de Algunos Aspectos de los Modelos Británico y Español

4. Apostilla

Referencias

Notas

Nota final

1. Introducción

El debate propuesto en esta sección de Vivat Academia sobre modelos de carrera universitaria es tanto más interesante y oportuno cuanto que a mi juicio está claro que en el momento actual se está abriendo en nuestro país un periodo de profunda reflexión y autocrítica sobre nuestro actual modelo universitario. Esta reflexión viene marcada sin duda por el bochorno desatado entre muchos académicos españoles por el famoso editorial de Nature (Diciembre de 1998) sobre la endogamia académica nacional, pero creo que, como está dejando claro el excelente foro de discusión propuesto por la AACTENOTA1, tiene mucho más alcance, yendo más allá del problema concreto del lamentable derrotero que ha seguido el sistema de contrataciones de investigadores y profesores en buena parte de nuestra universidad, 
y afectando en general a muchos aspectos del diseño y conceptualización de la institución universitaria.

Mi contribución a esta sección de Opinión y Debate de Vivat Academia pretende básicamente contraponer los sistemas británicos y español y discutir hasta qué punto nuestro modelo de enseñanza universitaria se puede beneficiar de la trayectoria del sistema británico de educación superior que, como es bien sabido, es uno de los mas prestigiosos internacionalmente (Shattock, 1999). La experiencia personal a partir de la que propongo esta discusión es la de sucesivos periodos como alumno, investigador y profesor dentro de los dos sistemas (estudiante de licenciatura y becario predoctoral con tareas docentes en la Universidad de Sevilla y estudiante de postgrado, becario postdoctoral y profesor en las universidades británicas de Southampton y Bradford).

En primer lugar haré una descripción sucinta de las principales características del sistema británico (creo que el español no necesita ser presentado para los lectores y lectoras de Vivat Academia) y luego comentaré qué tipo de lecciones pienso debemos de extraer de dicho modelo, concentrándome especialmente en el modelo general de universidad y en sus aspectos docentes más que investigadores (ya que entiendo que estos pueden resultar más relevantes para la comunidad de estudiantes españoles/as).

\section{Descripción del Modelo Británico.}

\subsection{Un Modelo Altamente Competitivo}

(2.1.a) Una primera característica definitoria del sistema universitario británico es su carácter fuertemente competitivo, ya que todos los departamentos universitarios están insertos en un sistema de evaluación periódica de sus rendimientos docente e investigador que impone no ya solo una constante actualización, sino la búsqueda activa de mejores resultados y más calidad. Esta evaluación periódica es doble. 
Por una parte, cada cinco años, los departamentos tienen que pasar el denominado ejercicio de evaluación investigadora o RAE (Research Assessment Exercise) en virtud del cual un panel de especialistas del ramo de nivel senior (normalmente catedráticos/as y directores/as de departamento) de otros centros estudia, analiza y puntúa los resultados de las investigaciones realizadas por cada departamento en los cinco años previos. Este ejercicio es patrocinado por el Higher Education Funding Council for England (Consejo de Financiación de la Educación Superior de Inglaterra) en colaboración con instituciones homólogas de Gales, Escocia e Irlanda del NorteNOTA2.

Para pasar el RAE quinquenal, cada departamento se prepara intensivamente en los meses precedentes preparando un documento sobre su producción científica que constituye de hecho la base utilizada por el panel de expertos/as para realizar la puntuación final. Básicamente el documento incluye tres tipos de informaciones:

Una lista de las cuatro publicaciones de mayor calidad y alcance realizadas por cada miembro del departamento en los cinco años previos.

Un informe sobre la cantidad general de fondos para la investigación captados por el departamento, sus fuentes y su uso.

Un informe sobre los denominados Indicadores de Reconocimiento (Indicators of Recognition), que básicamente intenta medir el impacto y aceptación de la labor investigadora de cada miembro del centro. La lista de indicadores en el caso de los departamentos de arqueología es la siguiente:

Trabajos y estudios de campo actualmente en desarrollo. 
Publicaciones en colaboración con colegas de otros países.

Cargos ejercidos en instituciones de otros países.

Pertenencia a asociaciones nacionales e internacionales.

Ejercicio de responsabilidades editoriales en revistas, series de libros o boletines internacionales.

Visitantes de otros países recibidos.

Organización de conferencias, sesiones en conferencias y encuentros.

Participación en tareas organizativas o de asesoramiento para organismos internacionales.

Clases, conferencias y charlas impartidas por invitación de instituciones extranjeras.

Examinador o supervisor externo (de asignaturas o doctorados).

Trabajos destinados a la divulgación pública del trabajo científico.

Cuando el peer-review del rendimiento investigador del departamento ha sido efectuado sobre la base de estos parámetros, el departamento recibe una puntuación que oscila de 1 a 5 (de pobre a excelente) con la posibilidad de un cinco con matrícula para los tres mejores departamentos del país (lo que suele incluir normalmente a Oxford y Cambridge casi por defecto). 
La calificación obtenida afectará en parte al grado de financiación que el departamento sea capaz de obtener en los cinco años subsiguientes, así como a su imagen y prestigio, lo que es crucial respecto al número de alumnos/as que soliciten registrarse en él.

En segundo lugar, todos los departamentos universitarios británicos pasan cada ocho años (puede o no coincidir en el mismo año que el RAE) una evaluación de la calidad docente y organizativa denominado Revisión de Materias (Subject Review). Este examen es realizado por un panel de expertos/as en la materia (en este caso de nivel junior o senior) coordinados por un/a académico/a senior de otro campo de conocimientos diferente. Todo el panel recibe un cursillo de preparación de dos días organizado por la Quality Assessment Agency (Agencia de Valoración de la Calidad) del Higher Education Funding Council for England (Consejo de Financiación de la Educación Superior)NOTA3. Como parte de ese cursillo se ponen ejemplos de situaciones en las que un departamento altamente incompetente e improductivo en su docencia puede ser clausurado.

El departamento examinado tiene la obligación de preparar con antelación un documento sintético en el que explique las virtudes y ventajas de su organización docente y administrativa, pero ello en ningún caso es óbice para que el panel visitante tenga, completa y absoluta libertad de movimientos. Una vez preparado para su tarea, el panel de Revisión de Materias pasa varios días (generalmente de tres a cuatro) visitando el centro en cuestión, consultando todo tipo de documentación administrativa y docente a discreción, asistiendo a clases, prácticas de laboratorio y todo tipo de actividades docentes (sin tener necesariamente que avisar con antelación) y entrevistando a profesores/as, administrativos/as, técnicos/as y alumnos/as. 
Como resultado de estas dos clasificaciones y otros indicadores, los medios de comunicación especializados (por ejemplo el conocido The Times Higher Education Supplement) han creado una clasificación de todos los departamentos y universidades del país, de forma que los alumnos en busca de titulaciones universitarias saben claramente qué pueden esperar de cada centro, y dónde deben dirigirse si buscan condiciones de excelencia. Esta clasificación, que es conocida habitualmente como la "liga universitaria", es publicada, debatida y comentada regularmente en periódicos y otros medios de comunicación.

Asimismo, como consecuencia de la dinámica competitiva existente, los departamentos siguen una política de contratación muy abierta, buscando afanosamente investigadores/as jóvenes talentosos/as y prometedores/as para asegurarse buenos rendimientos investigadores futuros. La dinámica de headhunting llega a veces a extremos insospechados en España, con algunos departamentos robándose figuras destacadas y de reconocido prestigio nacional e internacional para incorporarlas a sus plantillas y mejorar su propia calidad. En conjunto, debido a la necesidad de responder a la dinámica competitiva con propuestas y programas originales, con el paso del tiempo casi todos los departamentos punteros han acabado desarrollando una fuerte vocación internacionalista e interdisciplinarista: por ponerles un ejemplo, el Departamento de Ciencias Arqueológicas de la Universidad de Bradford incluye en su plantilla químicos, físicos, geólogos, antropólogos forenses, biólogos (y algún que otro arqueólogo) de cuatro nacionalidades diferentes aparte de la británica.

(2.1.b) En general, aparte de su fuerte carácter competitivo, una segunda característica del sistema universitario británico, que resulta especialmente interesante desde la perspectiva española, es la de su carácter no funcionarial. Los profesores universitarios, incluso aquellos que ostentan contratos permanentes, no son funcionarios/as de carrera que ostentan plazas vitalicias al modo de los/as 
profesores/as titulares o catedráticos/as de la universidad española. La mayoría de los/as profesores/as británicos/as (con la excepción de casos muy particulares que ostentan tenure) pueden ser despedidos en función de la situación financiera y/o académica de la institución para la que trabajan o en caso de graves dejaciones de sus responsabilidades. Esto no quiere decir, naturalmente, que todo el personal docente e investigador universitario trabaje sobre la base de contratos temporales: hay un amplio abanico de situaciones posibles, desde contratos anuales renovables hasta contratos permanentes (indefinidos) que de hecho equivalen a las plazas de profesor titular españolas. Esta característica del sistema universitario británico facilita notablemente la movilidad de personas, ideas y proyectos.

\subsection{Sistema Docente.}

Como resultado de la presión competitiva que el sistema impone en individuos y centros, la organización de toda la docencia en las universidades británicas está fuertemente orientada hacia la flexibilidad, la adaptabilidad y la auto-crítica.

Por un lado el diseño de los contenidos de los planes de estudio es muy flexible. Las asignaturas impartidas quedan por completo a elección y criterio de cada departamento, que debe considerar atentamente cuáles son los elementos que la realidad científica, técnica, social y laboral de su disciplina o campo de trabajo requiere en cada momento, para así ofrecer planes de estudios realistas y prácticos. Aunque existe una cierta cantidad de papeleo que cumplimentar, en comparación con el modelo español, dentro del británico las asignaturas pueden ser creadas o fulminadas casi literalmente de un día para otro a discreción del Consejo de Departamento en función de cómo vayan funcionando, de su grado de aceptación y de la realidad del mercado laboral (con las únicas limitaciones de los requerimientos técnicos que las mismas conlleven y la subsiguiente aprobación de la universidad). 
En todo caso, nunca es el perfil de la plantilla docente el que determina a priori las posibilidades docentes: más bien es al contrario, las necesidades docentes son las que determinan las responsabilidades docentes de cada profesor o profesora, así como, por supuesto, la estrategia de contrataciones de nuevos miembros.

Por otro lado, se presta mucha atención a los cuestionarios que los alumnos/as cumplimentan al final del desarrollo de cada asignatura puntuando y valorando múltiples aspectos del desarrollo de las mismas, desde la puntualidad del profesor, hasta la adecuación de los recursos bibliográficos, pasando por la claridad de las explicaciones, la atención del profesor o profesora a las consultas del alumnado, etc. Los resultados de estos cuestionarios pueden o no ser hechos públicos a nivel departamental y de cara al alumnado, dependiendo de la estrategia seguida por cada centro, pero en cualquier caso obran en poder del Director del Departamento, quien generalmente comenta privadamente con cada profesor los resultados, especialmente si son malos de forma consistente.

El proceso de seguimiento del rendimiento del alumno/a es muy comprensivo y minucioso, e incluye diversos elementos que no están presentes en el sistema español:

Así, por ejemplo, aunque la asistencia a clases (lectures) no es obligatoria (sí lo es la asistencia a seminarios y prácticas), dado que se constata una fuerte correlación entre la ausencia a clases y los suspensos, muchos departamentos hacen un seguimiento estrecho de la misma, enviando cartas personales a los alumnos que faltan a clase durante más de dos semanas seguidas sin justificación.

Asimismo, existe un sistema de tutorías según el cual cada profesor/a tiene a su cargo un numero variable de alumnos/as (tutees) de los que debe hacer un especial 
seguimiento, ayudándoles a solucionar problemas académicos y de estudio, especialmente con los/as estudiantes de primer curso (novatos/as).

Otro instrumento intensivamente utilizado para controlar la progresión de los/as alumnos/as es el de las sesiones de revisión (feedback sessions) para los ejercicios escritos (essays) prácticas de laboratorios, exámenes, etc. Generalmente se espera que cada alumno/a reciba de su profesor/a un comentario escrito de cada ejercicio realizado (máxime si cuenta para la nota final), lo que puede ir acompañado, a criterio de amas partes, de una entrevista personal. Este comentario escrito debe siempre (este es un punto constantemente reiterado) incluir referencias no solo a los defectos, omisiones o faltas que el trabajo del alumno/a presente, sino comentarios de los puntos fuertes del mismo y medidas a tomar para mejorar su rendimiento. Es decir, debe haber un gran componente positivo y constructivo en la valoración del trabajo del alumno/a, evitando siempre que sea posible resaltar tan solo las carencias y errores.

Finalmente, un elemento esencial del sistema de seguimiento del trabajo y rendimiento del alumnado es el de la doble corrección y corrección externa de exámenes y trabajos de curso, que se aplica para garantizar el máximo grado de veracidad y objetividad en las puntuaciones concedidas. Cada examen o ensayo debe ser corregido no solo por el/la profesor/a responsable, sino también por un/a segundo/a profesor/a, con quien la nota final debe ser consensuada. En el caso de los exámenes, se requiere además la participación de un/a examinador/a externo/a (de otra universidad) quien debe asimismo dar su visto bueno sobre las puntuaciones dadas y proponer modificaciones en su caso. El papel del/a examinador/a externo/a es asimismo clave en un momento anterior, cuando las propias preguntas del examen son propuestas, con meses de antelación. La corrección de los exámenes, es, dicho sea de paso, completamente secreta, ya que las respuestas son presentadas en impresos especiales donde el nombre del alumno/a 
queda oculto, no siendo revelado hasta el final del proceso, cuando se elaboran las actas.

Este modelo docente requiere de un gran esfuerzo (y mucha dedicación de tiempo) por parte de los/as profesores/as, quienes deben asegurarse de que todos los alumnos y alumnas sean objeto de un seguimiento y evaluación continuas. A cambio, el sistema ofrece bastantes garantías en cuanto a la constancia en la supervisión del progreso de los alumnos/as y en cuanto a la imparcialidad de su evaluación.

3. ¿Flexibilidad vs. Rigidez? Discusión Comparativa de Algunos Aspectos de los Modelos Británico y Español

No me cabe duda de que cualquiera de mis colegas de cualquier universidad española, y muchos de los alumnos/as más avezados/as y/o de cursos superiores, se habrán dado rápidamente cuenta de las considerables diferencias de concepción y funcionamiento docente que median entre los sistemas universitarios español y británico.

Creo que la mayoría de las diferencias fundamentales entre los dos sistemas se explican por el carácter competitivo del uno frente a la naturaleza más funcionarial del otro. Ello en buena parte obedece a razones históricas que explican la propia configuración de la res publica en el Reino Unido y en España (y Europa Occidental por extensión, en general), pero que aquí no hay tiempo de considerar. En general, por decirlo en pocas palabras, el sistema británico es bastante más flexible, adaptativo y práctico que el español.

En primer lugar, el modelo universitario español puede claramente beneficiarse de tomar nota de las consecuencias positivas que el sistema de evaluación de los resultados docentes e investigadores de cada centro está teniendo en el Reino Unido 
desde hace años. En nuestro país se están produciendo desde hace varios años intentos de progresar por la vía de valorar los rendimientos universitarios de una forma efectiva. Una iniciativa interesante es el Plan Nacional de Evaluación de la Calidad de las UniversidadesNOTA4, mientras que la iniciativa catalana de la Agència per a la Qualitat del Sistema Universitari a CatalunyaNOTA5 tiende a reproducir el modelo de la QAA británica anteriormente referida. En Andalucía se ha creado recientemente una Unidad para la Calidad de las Universidades AndaluzasNOTA6.

Estas iniciativas (sean autonómicas o nacionales) pueden ser muy beneficiosas si tienden sincera y operativamente a establecer una clasificación de los departamentos de cada especialidad que se haga de público conocimiento. Por otra parte, sus conclusiones pueden no tener mucho objeto si el marco general no se flexibiliza para permitir una más fuerte competencia.

La presión impuesta por el sistema de evaluación del rendimiento docente e investigador hace que el profesorado universitario británico muestre un alto grado de motivación para mantener aceptables niveles de actualización y eficacia y en busca de la excelencia: tal motivación está por completo ausente en el sistema español. Los/as profesores/as británicos no pueden permitirse dejar pasar años y años haciendo poca o ninguna investigación e impartiendo clases poco o nada preparadas porque, en última instancia, estarían cavando su propia tumba: pasado un cierto tiempo su centro podría llegar a ser considerado obsoleto y clausurado por la correspondiente agencia de calidad, y luego sus posibilidades de ser contratados/as por otra universidad serían nulas. En mi opinión, el sistema universitario español tiene mucho que aprender de esta aproximación al concepto de universidad. La universidad transmite conocimiento y formación de última generación (por decirlo con la afortunada expresión inglesa, cutting-edge) al público; este tipo de conocimiento cambia y evoluciona constantemente, lo que obliga los/as 
responsables/as de transmitirlo a estar atentos/as y no perder el hábito de estudiar y actualizarse.

El tradicional sistema funcionarial y de contratación de la universidad española representa de hecho un fuerte desincentivo para el mantenimiento de un alto nivel de motivación que posibilite la excelencia. De hecho, los datos de encuestas y estudios recientes muestran que una gran parte de los miembros de la comunidad universitaria española comparten esta opinión (El País, 8 de Septiembre de 1999 y Suplemento de Educación de El País, 31 de Enero de 2000)NOTA7. Un sistema como el británico muestra que es posible reconciliar la conveniencia de mantener una cierta y modesta cantidad de presión sobre los/as profesionales de la enseñanza universitaria (e investigadores/as) con la natural, humana y conveniente necesidad de una sensación de seguridad laboral que permita a las personas dedicarse a su trabajo con confianza.

Ahora bien, de la reciente experiencia británica conviene también extraer una cierta noción de que esa "presión" debe ser moderada y controlada, evitando que las "autoevaluaciones" y papeleos de control lleguen a estorbar por completo el desarrollo eficaz del trabajo de los profesores (jalgunos/as colegas británicos empiezan a tener una cierta y estresante sensación de que están aproximándose a ese tipo de situación!). El desarrollo de un sistema eficaz de evaluación permanente debe contar con un apoyo secretarial y administrativo adecuado para evitar que se convierta en una carga burocrática extra en las espaldas de los profesores/as, que es precisamente un efecto colateral indeseable que está comenzando a darse en el Reino Unido.

En segundo lugar, un aspecto en el que la sensación de flexibilidad vs. rigidez al comparar ambos modelos se acentúa es el de los planes de estudio. Mientras que en el Reino Unido los contenidos docentes quedan en última instancia como una 
decisión estratégica a tomar por cada departamento, en España implican grandes, dificultosas (y a menudo poco fructíferas) discusiones de ámbito nacional. Además, en las universidades británicas los planes de estudio se construyen sobre la marcha, y no hay rigideces ni trámites burocráticos interminables cuando se trata de algo tan simple como cambiar una asignatura por otra. Creo que una cosa muy positiva que el modelo universitario español podría hacer en el futuro sería posibilitar una mayor flexibilidad y espontaneidad en la forma en que los departamentos diseñen sus propios planes de estudio, con mayor autonomía y menores cantidades de papeleo.

Finalmente creo que la universidad española puede beneficiarse estudiando el modelo de interacción entre alumnos/as y profesores/as que se da en las británicas. Por una parte, los resultados de las encuestas cumplimentadas por los alumnos sobre la calidad docente deben ser objeto de una reflexión departamental en voz alta (y tono constructivo), pues de lo contrario carecen de sentido.

El sistema británico de tutorías, revisiones de exámenes y trabajos, y doble corrección y corrección externa de exámenes es extremadamente laborioso y requiere mucho tiempo y papeleo, pero garantiza un sistema de calificaciones más justo y equitativo. En el caso de nuestras universidades, evidentemente, la aplicabilidad de estos procedimientos queda muy a expensas del problema de la masificación: sin una relación viable entre número de alumnos y número de profesores es sencillamente impensable. De hecho, hay que tener en cuenta que numerosos aspectos del sistema universitario británico se explican por el carácter elitista que la institución ha tenido hasta muy recientemente, cuando ha empezado a verse afectada por un incipiente problema de masificación en parte similar al que vive desde hace años la universidad española. Todavía es pronto para decir como va a reaccionar el modelo británico cuando la masificación se agudice aún más.

4. Apostilla. 
En España hay en este preciso momento un candente debate abierto sobre el modelo de universidad que nuestro país necesita. Para evitar ciertos errores del pasado (como por ejemplo la catástrofe de las "idoneidades") y progresar, debemos tener la mente bien abierta y considerar las experiencias de países que por su historia reciente, riqueza o (sencillamente) nivel de organización, nos superan en la calidad del sistema universitario, y la iniciativa de Vivat Academia es muy positiva en ese sentido, sobre todo para los/as colegas y alumnos/as que no han tenido la oportunidad de conocer de primera mano otros modelos universitarios.

Mi disgresión sobre el modelo británico ha ido dirigida tanto a colegas investigadores/as y docentes como a alumnos/as. De hecho, sin embargo, creo que siento con especial fuerza la necesidad de transmitir esta discusión a los propios alumnos y alumnas españolas/es, porque en última instancia son ellas y ellos los que deben hacerse conscientes de las limitaciones de nuestro sistema y de cómo puede ser mejorado. El alumnado paga sus tasas y luego recibe una educación de calidad variable, pero que puede llegar a ser francamente pobre en algunos casos, lo cual claramente vulnera y lesiona los derechos de muchos de nuestros conciudadanos y conciudadanas más jóvenes, aparte de dañar el tejido social y profesional del país y suponer una dilapidación de recursos y del dinero del contribuyente.

\section{Referencias}

Shattock, M. (1999): "The Challenge Ahead: British Universities in the 21st Century." $\begin{array}{llll}\text { International Higher } & \text { Education } & 15 . & \text { Boston }\end{array}$ (http://www.bc.edu/bc_org/avp/soe/cihe/)

\section{Notas}

NOTA 1: http:/ / members.es.tripod.de/aacte/AACTE/aacte.html 
NOTA 2: http://www.rae.ac.uk/

NOTA 3: http://www.qaa.ac.uk/

NOTA 4: http://www.mec.es/consejou/calidadSet1.html

NOTA 5: http://www.agenqua.org/

NOTA 6: http://www.uca.es/UCUA/

NOTA 7: http://www.elpais.es/p/d/suplemen/educa/1edu31h.htm\#dos

Nota final

Debo agradecer los útiles comentarios que he recibido de varios colegas para escribir este breve artículo de opinión, especialmente del Dr. Robin Coningham, del Departament of Archaeological Sciences de la Universidad de Bradford y de la Dra. M. Díaz-Andreu, del Department of Archaeology de la Universidad de Durham.

Bradford 27 de Febrero de 2000

\section{TABACO Y UNIVERSIDAD}

\section{Por Dominux}

Ante todo, debo agradecer a la asociación A.DE.SA.N.FU por su colaboración al enviarme el Real Decreto en el que se exponen nuestros derechos. 
He aquí todos los derechos que la Universidad de Alcalá de Henares nos pisotea todos los días. Para que luego digan que no hablo con todas las de la ley:

REAL DECRETO 192/1988, DE 4 DE MARZO (B.O.E. de 9 de marzo) [ARANZADI 530], SOBRE LIMITACIONES EN LA VENTA Y USO DEL TABACO PARA PROTECCIÓN DE LA SALUD DE LA POBLACIÓN.

Todo ello exige que el Gobierno, consciente de esta realidad, adopte las medidas destinadas no sólo a reducir la inducción al consumo de tabaco, sino también a promover los legítimos derechos a la protección de la salud de los no fumadores;

Artículo 1. De acuerdo con lo establecido en el artículo 25.2 de la Ley General de Sanidad, se declara al tabaco sustancia nociva para la salud de la persona. En consecuencia, en caso de conflicto prevalecerá siempre el derecho a la salud de los no fumadores sobre el derecho de los fumadores a consumir labores de tabaco en todos aquellos lugares o circunstancias en que pueda afectarse al derecho a la salud de los primeros, conforme a los términos del presente Real Decreto.

Entonces, ¿Por qué no se prohibe fumar en TODOS LOS RECINTOS universitarios?.

Artículo 7. 1. No se permitirá fumar en:

a) Lugares donde exista mayor riesgo a la salud del trabajador por combinar la nocividad del tabaco con el perjuicio ocasionado por el contaminante industrial.

b) Cualquier área laboral donde trabajen mujeres embarazadas.

2. Con las excepciones señaladas en el artículo $8 .^{\circ}$ de esta disposición no se permitirá fumar en:

a) Centros de atención social destinados a menores de dieciséis años. 
b) Centros, servicios o establecimientos sanitarios definidos según el Real Decreto 2177/1978, de 1 de septiembre, por el que se aprueba el Registro, catalogación e inspección de Centros, servicios y establecimientos sanitarios.

c) Centros docentes.

d) Zonas de las oficinas de las Administraciones Públicas destinadas a la atención directa al público.

e) Locales donde se elaboren, transformen, preparen o vendan alimentos, excepto los destinados principalmente a consumo de los mismos, manteniéndose la prohibición de fumar a los manipuladores de alimentos, de acuerdo con el Real Decreto 2505/1983, sobre Reglamento de Manipuladores de Alimentos.

f) Salas de uso público general, lectura y exposición.

g) Locales comerciales cerrados con frecuente congregación de personas.

h) Salas de teatro, cinematógrafos y otros espectáculos públicos y deportivos en locales cerrados e identificados según el Real Decreto 2816/1982, de 27 de agosto, por el que se aprueba el Reglamento de Policía de Espectáculos Públicos y Actividades Recreativas.

i) Ascensores y elevadores.

j) Aeronaves en vuelo comercial cuyo origen y destino este en territorio nacional .

3. Se solicitará la colaboración de los Comités de Seguridad e Higiene en el Trabajo y los Comités de Empresa en la ejecución y en la vigilancia de estas normas.

¿La Universidad no es un centro Docente?, ¿No es un centro donde hay trabajadores?, ¿No hay atención al público?. Lo de los ascensores es una vergüenza.

Artículo 8. 1. Se habilitarán zonas diferenciadas para fumadores ostensiblemente señalizadas en los locales destinados a teatro y otros espectáculos públicos o deportivos cerrados, salas de espera de transporte colectivo y cualquier local donde exista prohibición de fumar. En caso de que no fuese posible delimitar lugares 
alternativos para fumadores se mantendrá la prohibición de fumar en todo el local, advirtiendo mediante una adecuada señalización al usuario.

He estado en todas la facultades y no he visto ni un solo cartel de área para fumadores, ¿No será que toda la universidad no es un área para No Fumadores?

Artículo 9. En todos los casos los titulares de los medios de transporte de los locales y establecimientos mencionados en los artículos $6 .^{\circ}, 7 .^{\circ}$ y $8 .^{\circ}$, serán responsables del estricto cumplimiento de estas normas. Asimismo, estarán obligados a señalizar las limitaciones y prohibiciones, y deberán contar con hojas de reclamación a disposición de los usuarios, que habrán de ser informados de la existencia de dichas hojas de reclamación.

Lo cual demuestra que la universidad, así como sus vicerrectores son los responsables de lo que ocurre allí dentro, pero claro; están tan ocupados de banquete en banquete, de cena en cena, de concierto en concierto (Aunque por su poca cultura musical aplaudan cuando no deban, y si no me creen, deberían haber ido al concierto para piano a cuatro manos celebrado en la Escuela Politécnica).

Artículo 11.4. Son infracciones sanitarias leves:

a) La falta o incorrecta señalización de las zonas o áreas a que se refiere el artículo $8 .^{\circ}$

b) La ausencia de hojas de reclamación a disposición de los usuarios.

Qué curioso, la Universidad comete una (¿o dos?) faltas sanitarias leves.

\section{DISPOSICIONES ADICIONALES}

Primera.- Lo dispuesto en el presente Real Decreto es de aplicación en todo el territorio nacional, sin perjuicio de las competencias en materia de sanidad interior 
que tienen atribuidas las Comunidades Autónomas que las ostentan en el marco del artículo 149 de la Constitución.

\section{ANEXO}

Lista de advertencias relativas a la salud contemplada en el apartado 2 del artículo 5.

1. Fumar provoca cáncer.

2. Fumar provoca enfermedades cardiovasculares.

3. Fumar durante el embarazo daña al futuro hijo.

4. Proteja a los niños, no les haga respirar el humo del tabaco.

5. Fumar provoca cáncer, bronquitis crónica y otras enfermedades pulmonares.

6. Fumar perjudica a los que le rodean.

Si ya lo venía Yo diciendo....

Más preciso y legal no se puede ser. Por qué debo aguantar esta situación!. ¿Por qué no se me permite rociar a los fumadores con gas mostaza y ellos me pueden escupir su cáncer?.

\section{INCONGRUENCIAS}

Por Julio Gutiérrez. Universidad de Alcalá

Una revista indeseable

Más o menos, esa es la consideración que Vivat Academia merece a las autoridades universitarias de Alcalá de Henares y a algunos otros miembros de la comunidad, como pueden ser ciertos responsables del Consejo de Estudiantes: una revista indeseable. De eso estábamos seguros y no hacía falta intentar obtener una prueba; sus razones tendrán. No obstante, por aquello de "si cuela", envié una solicitud al 
Servicio de Información para que se anunciara la existencia de esta publicación en los tablones electrónicos que la UA ha instalado en diversos lugares. Tenía la completa seguridad de que me contestarían con un NO, porque "la información que difundimos no es de interés general". Y ello pese a que en esos paneles se difunden todo tipo de noticias, algunas de ellas dirigidas a un grupo muy restringido de universitarios $\mathrm{y}$, desde luego, sin que tengan que ver con eventos institucionales.

Así ha sido, como pueden ver en la respuesta que reproducimos:

copia del mensaje electrónico recibido:

\section{Asunto:}

Fecha: Thu, 23 Mar 2000 18:10:56 +0100

De: "Medina de la Vega M. Isabel" maribel.medina@uah.es
A: Gutierrez Muñoz Julio julio.gutierrez@uah.es
CC: "Gutierrez, Luis Miguel" luism.gutierrez@uah.es

Estimado Sr. Gutiérrez:

El Servicio de Información me ha trasladado copia de la solicitud que Ud. dirige, relativa a la inclusión de información en los paneles electrónicos de la Universidad sobre Vivat Academia.

Dado que la única información que se incluye en los mismos, es aquella de carácter institucional e interés general para la comunidad universitaria, lamento no poder atender su petición.

Olga Rius Gázquez Gerente 
Se preguntarán ustedes: ¿Dónde está la incongruencia?

Les ruego que lean atentamente el "e-milio" y me sugieran soluciones al enigma: Mi petición fue cursada a D. Luis Miguel Gutiérrez; la respuesta proviene de Dña. Isabel Medina, con copia al anterior; por último, la nota viene firmada por Dña. Olga Rius. Yo tengo una explicación, que no creo sea la adecuada: Estamos ante un caso de "Trinidad Informática", es decir, tres personas distintas y un sólo gestor verdadero. ¿Me equivoco?.

Un listín telefónico poco económico

La UA ha procedido a reeditar su directorio telefónico, iperfecto! Pero he aquí que se ha cambiado por una edición mucho más costosa y difícil de consultar que la precedente, consistente en una carpeta de anillas. Una actualización que, antes suponía cambiar unas pocas páginas, significa ahora la reedición de dos volúmenes completos.

Pero no acaba ahí la incongruencia. Resulta que cuando fuimos ilusionados a consultarlo, después de años de esperar la puesta al día, pensando, ingenuos, que por fin tendríamos la información deseada, nos hemos encontrado con personas que hace meses que se fueron de esta universidad, con números de teléfono equivocados y con cargos que no se corresponden con las personas que los desempeñan. Para remediarlo, no se dice en parte alguna de la publicación quién es el responsable de la misma, ni la fecha de edición. ¿Se imaginan la guía de Telefónica sin que figure, al menos en su portada, el año a que corresponde? 


\section{Un puente torcido}

Hace un par de números aplaudíamos la construcción del puente que da acceso a la vía de servicio de la carretera Nacional II, al este del Campus. ¡La de tiempo y kilómetros que ahorramos! Pero ya antes de terminar observamos, incrédulos, que la obra parecía estar inclinada hacia un lateral. Pensamos que era un efecto óptico, pero, una vez inaugurada, de efecto nada. ¡El puente, construido en línea recta, está peraltado! ¿Se perdería el ingeniero la clase de Física correspondiente, donde se explica para qué sirven los peraltes? Nos tememos que sí, y ello supone un peligro, dada la estrechez de la calzada, sobre todo teniendo en cuenta que las heladas, en esta zona, son muy comunes.

Además, como es habitual en la Universidad de Alcalá, no acaba ahí la incongruencia. La estrechez antes aludida implica la imposibilidad de recorrer el acceso a pie, salvo para aquellos que gustan del riesgo y, más aún, habida cuenta del "quita miedos" que impide salirse en catástrofe. Tratándose de una obra completamente nueva, ¿resultaba realmente mucho más caro hacerlo en buenas condiciones? Para otras cosas menos importantes no se escatima el gasto, afirmo.

El daño a la Institución

Quedamos estupefactos tras leer las declaraciones de Jaime Vinuesa, rector de la Universidad de Cantabria, con motivo de la polémica puesta en servicio de un control estudiantil al profesorado, quien entre otras cosas dijo:

"se ha hecho "un daño irreparable" a la universidad"

además de exigir una "rectificación pública" de quienes han vertido "declaraciones irresponsables" en contra del procedimiento. 
¿Qué significa esto? ¿Otro rector que se apunta al perfil dictatorial de los que se atreven a identificar su persona con las instituciones a las que representan? Nuestro rector, Manuel Gala, ya nos tiene acostumbrados a estas identificaciones, pero la enfermedad parece ser contagiosa, $y$, al parecer, amenaza con convertirse en pandemia.

Señores rectores, las críticas a sus decisiones, sean personales, provengan de Junta de Gobierno, o de cualquier otro órgano personal o colegiado, no atentan contra la institución ni de lejos. Ustedes no están por encima del bien y del mal, ¿o sí? La divinidad de los césares hace tiempo que dejó de ser un factor social. Las críticas podrán ser más o menos virulentas, pero van dirigidas a sus errores o, al menos, a lo que entendemos como errores los gobernados. Salgan de su "torre de marfil" y tomen conciencia de que la comunidad que los eligió desea otras cosas. Hasta el mismísimo Dios dijo en cierta ocasión "he venido a servir, no a ser servido". Despierten, por favor.

Avance en la calidad de la docencia en la UA

Nos hemos sorprendido "gratamente" con el esfuerzo que están haciendo nuestras autoridades académicas por mejorar la calidad de la docencia en la Universidad de Alcalá. Recientemente hemos recibido una información relativa a la disponibilidad de los programas de las asignaturas en la WEB de la UA. Uno de los párrafos del texto remitido dice:

Dicha acción ha resultado del proceso de Evaluación Institucional desarrollado dentro del Plan Nacional de Evaluación de la Calidad de las Universidades, como 
mejora en la Enseñanza y está siendo promovida por el Vicerrectorado de Ordenación Académica y Planes de Estudios.

¿Se van a quedar, como viene siendo habitual, en las formas? Porque, sin miedo a equivocarnos, opinamos que hay otras muchas conclusiones de la mencionada evaluación que no se están teniendo en cuenta. Prueba de ello es que los presupuestos para este año siguen estando volcados, prioritariamente, en la compra o restauración de edificios que no necesitamos.

El actual equipo de gobierno prometió, en las pasadas elecciones rectorales, tras copiar y/o asumir la casi totalidad de mi programa, la puesta en marcha de muchas iniciativas para mejorar la calidad de la docencia. Ya han pasado dos años, ¿dónde están esas promesas? (Esta pregunta va también dirigida al señor García).

\section{Guardar información}

El señor vicerrector de Asuntos Económicos y Estudiantes proclamó, en la última sesión del Claustro de la Universidad de Alcalá, que el equipo de gobierno nunca había ocultado información a la comunidad universitaria. Estaba dispuesto, dijo, a recibir en su despacho a todo aquel que lo deseara y a explicarle lo que hiciera falta, o darle la información deseada. ¿Cómo se compagina esta "disponibilidad" con el hecho de haber negado, al que esto escribe, información solicitada por escrito?

Efectivamente, durante las pasadas elecciones a rector, en mi calidad de candidato, solicité al vicerrector Gonzalo Angulo la lista de becarios de la UA adscritos a los diferentes servicios de la misma y que hacen funciones de PAS. Asimismo solicité, también por escrito, al señor secretario general, los textos de los convenios que la UA tiene suscritos con diferentes entidades bancarias, estuvieran o no en vigor. En ambas 
casos se me negó la información solicitada, usando el argumento de la seguridad y la confidencialidad de los datos solicitados. Lo cual, sea dicho de paso, es falso por cuanto, los unos han de ser elegidos mediante concurso público y los otros han de ser aprobados por los órganos competentes. ¿A qué jugamos?

En la mencionada sesión del Claustro no intervine en este sentido, porque ya había sido demasiado largo y crispado el debate sobre los presupuestos. Pero, al igual que entonces le dije que era una burla maquillar los datos sobre la deuda acumulada de la UA, ahora le digo que se burló usted de nosotros cuando aseguró que no "guardan" información. Por cierto se la volveré a solicitar. 